OPEN ACCESS

Edited by:

Francesca Sanguedolce,

University of Foggia, Italy

Reviewed by:

Wen Kong,

Shanghai JiaoTong University, China

Liu Yiqiang,

Beijing Cancer Hospital, China

*Correspondence:

Huiling Wang

wanghuiling@gdph.org.cn

Zhi Li

lizhi20203939@163.com

${ }^{\dagger}$ These authors have contributed equally to this work and share first authorship

Specialty section: This article was submitted to Genitourinary Oncology. a section of the journal

Frontiers in Oncology

Received: 13 October 2021 Accepted: 08 November 2021 Published: 30 November 2021

Citation:

Ge $Y$, Lin $X$, Zhang $Q$, Lin D, Luo L, Wang $H$ and $L i Z$ (2021) Xp11.2 Translocation Renal Cell Carcinoma With TFE3 Rearrangement: Distinct Morphological Features and Prognosis With Different Fusion Partners.

Front. Oncol. 11:784993. doi: 10.3389/fonc.2021.784993

\section{Xp11.2 Translocation Renal Cell Carcinoma With TFE3 Rearrangement: Distinct Morphological Features and Prognosis With Different Fusion Partners}

\author{
Yan Ge ${ }^{1 \dagger}$, Xingtao Lin ${ }^{1 \dagger}$, Qingling Zhang ${ }^{1}$, Danyi Lin ${ }^{1}$, Luqiao Luo ${ }^{1}$, Huiling Wang ${ }^{2 *}$ \\ and $\mathrm{Zhi} \mathrm{Li}^{1 *}$ \\ ${ }^{1}$ Department of Pathology, Guangdong Provincial People's Hospital/Guangdong Academy of Medical Sciences, Guangzhou, \\ China, ${ }^{2}$ Department of General Surgery, Guangdong Provincial People's Hospital/Guangdong Academy of Medical \\ Sciences, Guangzhou, China
}

Background: Renal cell carcinoma (RCC) associated with Xp11.2 translocation/TFE3 gene fusion is a rare and new subtype of RCC and was classified by the WHO in 2004. Since then, multiple 5' fusion partners for TFE3 have been reported; however, the impact of individual fusion variant on specific clinicopathologic features of Xp11.2 RCCs has not been well defined.

Methods: Four Xp11.2 translocation RCCs were identified by morphological, immunostaining, and fluorescence in situ hybridization (FISH) assays from 200 patients who attended Guangdong General Hospital between January 2017 and January 2020. All these four cases were further analyzed by RNA sequencing to explore their TFE3 gene fusion partners. The clinicopathologic features, including clinical manifestations, pathological findings, treatment strategies, clinical outcomes, and follow-up information on Xp11.2 translocation RCCs, were recorded and evaluated.

Results: These four cases affected one male and three females. The median age was 13 years at the time of diagnosis (range $=4-20$ years). All the examined tumors were unilateral and unifocal. The largest diameter of these tumors ranged from 2.0 to $10.0 \mathrm{~cm}$, and the average was $5.55 \mathrm{~cm}$. Regional lymph node or distant metastasis developed in two patients. Three cases demonstrated known fusions: ASPCR1-TFE3 (two cases) and PRCC-TFE3 (one case). However, one case showed an unreported VCP-TFE3 fusion gene in Xp11.2 translocation RCCs. Immunohistochemistry results revealed tumor cells diffusely positive for TFE3, but have no consistency in other markers. Moreover, there were different clinical prognoses among the different variant TFE3 rearrangements; RCC patients with VCP-TFE3 translocation had worse prognosis compared to those with other fusion types. Follow-up were available for all the patients and ranged from 3 to 36 months. 
Three patients were without evidence of disease progression, while that with VCP-TFE3 fusion died of the disease 3 months after the diagnosis.

Conclusion: In conclusion, our data expand the list of TFE3 gene fusion partners and the clinicopathologic features of Xp11.2 RCCs with specific TFE3 gene fusions. We identified a novel VCP-TFE3 fusion in Xp11.2 translocation RCCs for the first time, which has unique morphology and worse prognosis than those with other variant TFE3 rearrangements. Integration of morphological, immunohistochemical, and molecular methods is often necessary for the precise diagnosis and optimal clinical management of malignant tumors.

Keywords: TFE3, VCP, renal cell carcinoma, Xp11.2 translocation, rearrangement

\section{INTRODUCTION}

Xp11.2 translocation carcinoma was first recognized as a subtype of renal cell carcinoma (RCC) in the 2004 World Health Organization classification of renal tumors (1), followed by being renamed as MiT (microphthalmia-associated transcription factor) family translocation renal cell carcinoma (tRCC) in the 2016 edition (2). Although this neoplasm is rare (1-4\%) since the incidence is estimated to all renal tumors, it is frequently observed in children and adolescents and was reported to account for $20 \%-75 \%$ of pediatric renal neoplasms (3). The prognosis of Xp11.2 RCC is still unclear because of the low appearance of series including a great number of patients and the short follow-up period (4).

TFE3, a transcription factor specifically recognizing E-box sequences, is a major regulator of both Golgi and lysosomal homeostasis. Multiple $5^{\prime}$-fusion partners for TFE3 have been reported. The most common gene fusion partners are $A S P L$ (alias ASPCR1) and PRCC; other fusion partners include CLTC, DVL2, LUC7L3, KHTFESRP, PARP14, NonO, SFPQ (alias PSF), MED15, RBM10, NEAT1, KAT6A (5), MATR3, FUBP1 (6), SETD1B (7), and EWSR1 (8). The result of translocation involving the TFE3 gene is the overexpression of the TFE3 protein. As a result of these translocations, the expression of the TFE3 fusion protein increases in the nuclei of tumor cells. Some authors have suggested that specific translocation has an influence on histological appearance (9). In this study, we used fluorescence in situ hybridization (FISH) to confirm four Xp11.2 tRCCs among 200 RCCs and used targeted RNA sequencing to identify the fusion genes in these four cases of Xp11.2 tRCCs. In recent years, the identification of chromosomal translocations and fusion genes has substantially contributed to diagnostic precision, enabling better understanding of the genetic mechanisms underlying carcinogenesis, thus leading to better risk stratification and the development of novel therapeutics.

\section{MATERIALS AND METHODS}

A retrospective study was performed among 200 cases diagnosed as RCC. These cases were collected from the Department of Pathology, Guangdong Provincial People's Hospital/Guangdong
Academy of Medical Sciences between January 2017 and January 2020. The clinicopathologic features, such as clinical manifestations, pathological findings, treatment strategies, clinical outcomes, and follow-up information on Xp11.2 tRCCs, were recorded and evaluated. All patients have signed an informed written consent to have their medical record data used in research.

\section{Immunohistochemistry}

Immunohistochemistry was performed on $4-\mu \mathrm{m}$ sections from formalin-fixed, paraffin-embedded (FFPE) tissue. The following antibodies were used, as previously described (10): HMB45 (HMB45, 1:400; Gene Tech, Shanghai, China), Melan A (A103, 1:4,000; Gene Tech, Shanghai, China), CK7 (OV-TL12/30, 1:3,200; Gene Tech, Shanghai, China), S100 (2A10, 1:400; IBL, Takasaki, Japan), cytokeratins AE1/3 (AE1/AE3, 1:400; Gene Tech, Shanghai, China), AMACR (13H4, 1:300; Gene Tech, Shanghai, China), Ki-67 (MIB-1, 1:30; BioGenex, Fremont, CA, USA), PAX8 (ZR-1, 1:800; Abcam, Cambridge, UK), CD10 (56C6, 1:200; Gene Tech, Shanghai, China), and TFE3 (MRQ-37, 1:1,000; MXB Biotechnologies, Fuzhou, China). The TFE3 antibody recognizes the C-terminal portion of the TFE3 protein. Tumor cells that were diffusely positive in nuclei were considered as strong positive. FISH detection would be recommended.

\section{TFE3 Break-Apart FISH Analysis}

FISH was performed on $4-\mu \mathrm{m}$ tissue sections with two colored split-apart probes for TFE3 (Z-2109-50; ZytoVision, Bremerhaven, Germany). The orange fluorochrome direct labeled probe hybridizes distal to the TFE3 gene; the green fluorochrome direct labeled probe hybridizes proximal to that gene. Briefly, the tumor area on the slides was marked with a diamond-tipped pen. The slides were deparaffinized in xylene, rehydrated, treated in $750 \mathrm{U} / \mathrm{ml}$ pepsin digest solution (SigmaAldrich, Natick, MA, USA) for $10 \mathrm{~min}$, and incubated in $10 \%$ buffered formalin for $10 \mathrm{~min}$. The slides and probes were separately denatured, and hybridization was performed at $37^{\circ} \mathrm{C}$ overnight. Post-hybridization wash was done in $0.4 \times \mathrm{SSC} / 0.3 \%$ $\mathrm{NP}-40$ at $73^{\circ} \mathrm{C}$ for $3 \mathrm{~min}$, and then the slides were counterstained with DAPI. A positive score was interpreted when at least $20 \%$ of the nuclei show a split-apart signal. Nuclei with incomplete sets of signals were omitted from the scoring. 


\section{RNA Sequencing}

Four cases that demonstrated positive results for the TFE3 breakapart FISH assay were analyzed by RNA sequencing. Total RNA from FFPE samples was extracted after xylene deparaffinization using the RNeasy FFPE Kit (Qiagen, Hilden, Germany). Ribosomal RNA was depleted using RNase $\mathrm{H}$, followed by library preparation using the KAPA Stranded RNA-seq Kit with RiboErase (HMR) (KAPA Biosystems, Wilmington, MA, USA). The library concentration was calculated using a KAPA Library Quantification Kit (KAPA Biosystems), and the library quality was assessed using the Agilent High Sensitivity DNA Kit and Bioanalyzer 2100 (Agilent Technologies, Santa Clara, CA, USA), followed by sequencing on the Illumina HiSeq nextgeneration sequencing (NGS) platform (Illumina, San Diego, CA, USA). Three tools were used for the detection of any potential TFE3 fusion of the RNA sequencing data. FusionCatcher (version 0.994e) was used with parameters (otherwise, the default parameter was used) that allowed the Bowtie aligner to perform both transcriptome and genome mapping, and the BLAT aligner was then used to further map unmapped reads and count fusion supporting evidence. The other two tools, Factera and Socrates (https://github.com/jibsch/Socrates), were both executed suing default parameters. Specifically, Socrates takes the modified BAM file, which converts the hard clip in the original BAM file into a soft clip to improve the fusion detection performance. The combined fusion results from all tools were manually reviewed on the Integrative Genomics Viewer for confirmation.

\section{RESULTS}

\section{Clinicopathologic Features}

We reviewed 200 nephrectomy cases and identified four Xp11.2 tRCCs. The clinicopathological findings are summarized in Table 1. These four cases affected one male and three females. The median age was 13 years at the time of diagnosis (range $=4-$ 20 years). Three tumors occurred in children. The last one occurred in an adult. All the examined tumors were unilateral and unifocal. Regional lymph node or distant metastasis developed in two patients. Follow-up was available for all patients and ranged from 3 to 36 months. Three patients were without evidence of disease progression, while one died of the disease 3 months after the diagnosis. Two patients presented with pT1 stage, two with pT2, and one with pM1.

The largest diameter of the tumors ranged from 3.0 to $10.0 \mathrm{~cm}$, with an average of $5.55 \mathrm{~cm}$. Macroscopically, the cut surface was usually solid and cystic with a sulfur yellow color, the same as that seen in clear cell RCC. Foci of necrosis, hemorrhage, and peritumor calcification were occasionally noted as well. In our cohort, no rhabdoid morphology was observed. Three cases demonstrated known fusions: ASPL-TFE3 (two cases) and PRCC-TFE3 (one case). One case showed an unreported fusion type: VCP-TFE3 in Xp11.2 tRCC. The predominant architectural appearance of the PRCC-TFE3 case was solid with a predominantly eosinophilic cytoplasm. The cell size was relatively consistent, small to medium size. No psammoma body was noticed. On the other hand, the histological appearance of the $A S P L-T F E 3$ group was branching papillary composed of clear/ eosinophilic cells with voluminous cytoplasm. The cell size was relatively larger than that of other fusion types. The psammoma body was easily seen. However, one case showed the VCP-TFE3 fusion gene. This tumor demonstrated a solid nested/alveolar architecture featuring epithelioid cells with a predominantly eosinophilic to a focal clear cytoplasm. The morphology is very similar to that of clear cell RCC. No psammoma body was noticed. All these four cases did not have a melanin pigment. Representative pictures are displayed in Figure 1.

\section{IHC Findings, FISH Validation, and Fusion Transcripts by RNA Sequencing}

The results of immunohistochemistry are summarized in Table 2. The four examined cases were all negative, with cytokeratin antibodies (CK7 and AE1/AE3), melanocytic markers (S-100, Melan A, and HMB45), and strong expressions of CD10, AMACR, and PAX8. The expressions of vimentin and AMACR are rare and focal. The diagnostic TFE3 reaction strongly labeled the nuclei in all cases (Figure 1E). FISH analysis with the TFE3 (Xp11) break-apart probe was positive for a TFE3 translocation.

All four neoplasms with known TFE3 immunohistochemistry and the TFE3 split FISH assay were analyzed by RNA sequencing for fusion partners. Gene fusions were successfully detected in four cases, of which three cases (75\%) showed relatively common gene fusions, including ASPSCR1/ASPL-TFE3 gene fusions (two cases) due to $\mathrm{t}(\mathrm{X} ; 1)(\mathrm{p} 11.2 ; \mathrm{q} 21)$ and a PRCC-TFE3 gene fusion (one case) due to $\mathrm{t}(\mathrm{X} ; 17)(\mathrm{p} 11.2 ; \mathrm{q} 25.3)$. Furthermore, we found a new VCP-TFE3 gene fusion due to $\mathrm{t}(\mathrm{x} ; 9)(\mathrm{p} 11.23 ; \mathrm{p} 13.3)$ in our cohort (Figure 2).

\section{DISCUSSION}

Xp11.2 tRCCs have two predisposing stages: pediatric population with a mean age of 17 years (11) and the adult population with a mean age of 37 years (4). We reviewed 200 nephrectomy cases

TABLE 1 | Clinicopathological characteristics of four cases of Xp11.2 renal cell carcinoma.

\begin{tabular}{|c|c|c|c|c|c|c|c|}
\hline & Age & Sex & Side & Diameter (cm) & pT stage & Follow-up (months) & TFE3 fusion type \\
\hline 1 & 9 & Male & Right & 3.0 & T1aN1M0 & 36 & $A S P L$ \\
\hline 2 & 20 & Female & Left & 10.0 & T2NOMO & 36 & PRCC \\
\hline 3 & 4 & Female & Left & 2.7 & T2NOMO & 30 & ASPL \\
\hline 4 & 17 & Female & Left & 6.5 & T3N?M1 & 3 & VCP \\
\hline
\end{tabular}




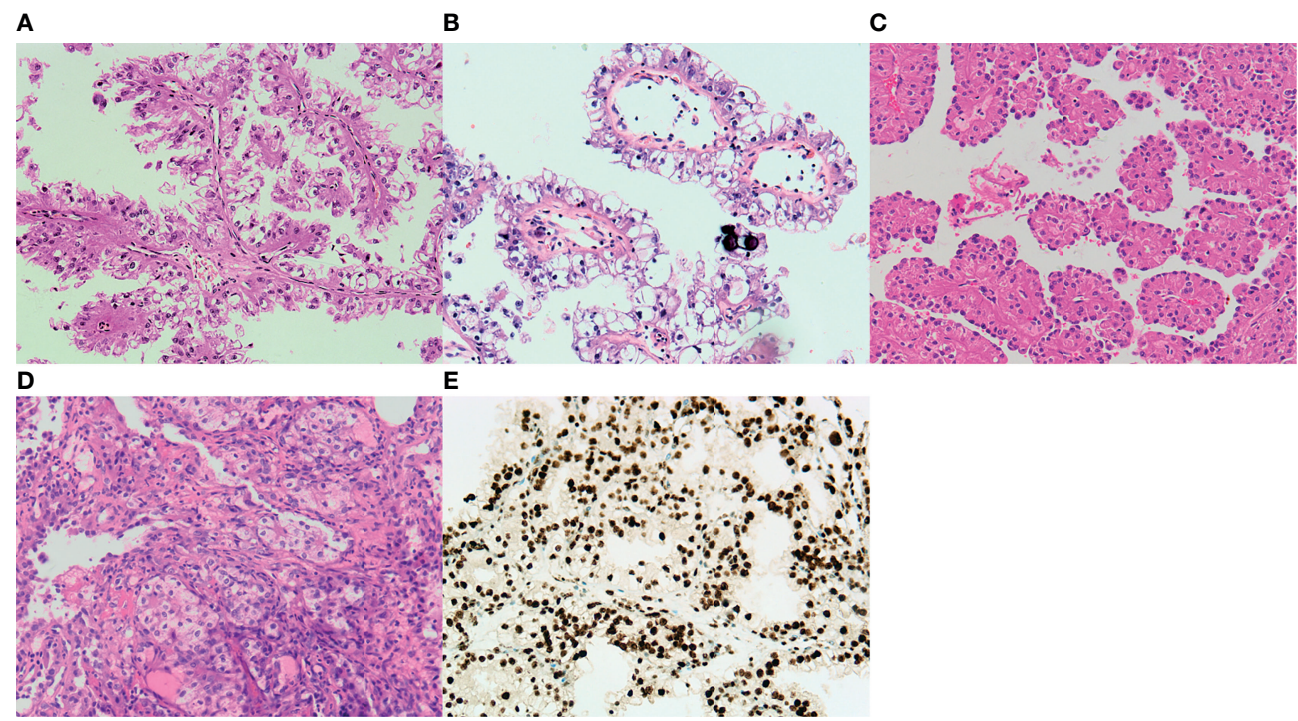

FIGURE 1 | Representative images of the typical morphological features of Xp11.2 translocation renal cell carcinoma (RCC). (A) ASPL-TFE3 fusion type shows a predominantly papillary morphology lined by pseudostratified clear to oncocytic cells. (B) Psammoma bodies are also present in ASPL-TFE3 Xp11.2 translocation RCC. (C) An alveolar pattern or organoid pattern populated by eosinophilic cells is noticed in the PRCC-TFE3 fusion type. (D) Xp11.2 translocation RCC with a novel fusion partner. VCP demonstrates a solid nested/alveolar pattern with predominant eosinophilic cells to focal clear cytoplasm. (E) Diagnostic TFE3 reaction strongly labeled the nuclei in the VCP-TFE3 fusion type. All images have a magnification factor of $\times 200$.

TABLE 2 | Immunohistochemistry, fluorescence in situ hybridization (FISH), and fusion type profiles of four cases of Xp11.2 renal cell carcinoma.

\begin{tabular}{|c|c|c|c|c|c|c|c|c|c|c|c|c|c|}
\hline & CA-9 & CK7 & $\mathrm{AE} 1 / 3$ & AMACR & CD10 & PAX-8 & S-100 & Melan A & HMB45 & Ki67 & TFE3 IHC & TFE3 FISH & TFE3 fusion type \\
\hline 1 & $\mathrm{~N}$ & $N$ & $N$ & $\mathrm{~F}$ & $\mathrm{D}$ & $\mathrm{F}$ & $\mathrm{N}$ & $\mathrm{N}$ & $N$ & $3 \%$ & $\mathrm{D}$ & + & $A S P L$ \\
\hline 2 & $\mathrm{~N}$ & $\mathrm{~N}$ & $N$ & $\mathrm{~F}$ & $D$ & $D$ & $\mathrm{~N}$ & $\mathrm{~N}$ & $N$ & $2 \%$ & D & + & PRCC \\
\hline 3 & $\mathrm{~N}$ & $\mathrm{~F}$ & $\mathrm{~F}$ & $\mathrm{~F}$ & $\mathrm{D}$ & $\mathrm{D}$ & $\mathrm{N}$ & $\mathrm{N}$ & $N$ & $10 \%$ & $\mathrm{D}$ & + & ASPL \\
\hline 4 & $N$ & $N$ & $N$ & $\mathrm{~F}$ & $\mathrm{D}$ & $\mathrm{D}$ & $\mathrm{N}$ & $\mathrm{N}$ & $\mathrm{N}$ & $12 \%$ & $\mathrm{D}$ & + & $V C P$ \\
\hline
\end{tabular}

$N$, negative; F, focally positive; $D$, diffusely positive; IHC, immunohistochemistry.

and identified four Xp11.2 tRCCs. In our study, three tumors affected children, and the oldest patient examined was 20 years old. The clinicopathological features of this cohort could probably represent the biological behavior of this rare cancer in young patients. In our cohort, the frequency of tRCC was the same as that in literature data $(2.0 \%$ vs $1 \%-4 \%)$ (12). Three patients were symptomatic, and tumor-related pain was the most common symptom. Unlike other patients, the first symptom of the patient with $V C P-T F E 3$ fusion was the presence of several bone metastases. She suffered from right hip pain for 1 month, and pain was aggravated with pathological fracture for 1 day. No patient had prior history of malignancy in our study. Clinically, Xp11.2 RCCs most commonly present as a sizeable mass in the kidney. The mean size of the tumors in this study was $5.55 \mathrm{~cm}$, which was smaller than that in an earlier reported series (13). An invasion of the vein and the sinus was noticed in one of the patients, the same as in the literature (14). Metastatic spread to the regional lymph nodes or distant organs was observed in two of the cases (the patient with VCP-TFE3 and one of the patients with $A S P L-T F E 3$ fusion). The patient with VCP-TFE3 fusion was first diagnosed at the pM1 stage.
Immunohistochemical staining is routinely used for the diagnosis of Xp11.2 tRCCs since the morphological features of these tumors commonly overlap those of other RCCs (15). TFE3 immunohistochemical staining is helpful in labeling the TFE3 protein, which is generally undetectable in normal tissues by immunohistochemistry. Moderate to strong nuclear TFE3 expression should be considered as genuinely positive, and FISH detection or RNA sequencing could be recommended. The renal tubular transcription factor PAX8 and other renal markers, such as CD10 and renal cell carcinoma marker (RCCMat), are consistently positive. The expressions of melanocytic markers (S100, Melan-A, and HMB-45) are frequent in TFEB tRCC, nevertheless are rare in Xp11.2 tRCCs (16). Unlike other adult RCCs, Xp11.2 RCC tends to underexpress epithelial markers (CK7 and AE1/AE3). A minimally positive carbonic anhydrase 9 (CA-9) signal differentiates Xp11.2 RCCs from clear cell RCCs, which consistently show diffuse CA-9 positivity (17).

Although the predominant growth patterns are papillary, tubular, nested, and mixed, the predominant histological characteristic of TFE3/Xp11.2 RCC is papillary architecture with clear cells and psammoma bodies. Contrasting conventional 
A

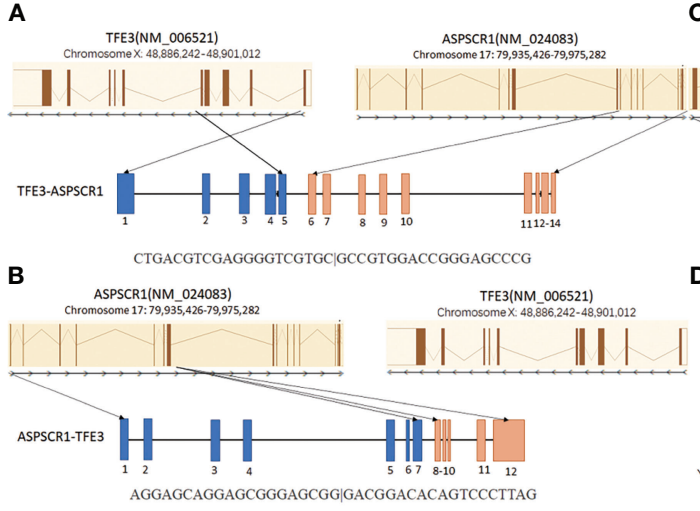

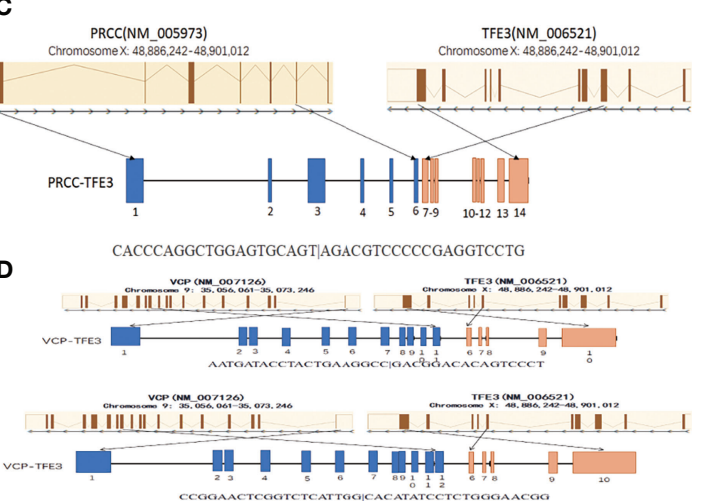

FIGURE 2 | Schematic diagrams of the TFE3 fusion transcripts with their partner genes in our cohort. (A) The ASPL-TFE3 rearrangement between genes ASPL exon 8 and TFE3 exon 5. (B) The ASPL-TFE3 rearrangement between genes ASPL exon 7 and TFE3 exon 6. (C) The PRCC-TFE3 rearrangement between genes PRCC exon 6 and TFE3 exon 3. (D) There are two VCP-TFE3 fusion types: one between VCP exon 11 and TFE3 exon 6 and the other between VCP exon 12 and TFE3 exon 6.

RCCs, Xp11.2 translocation-associated tumors are defined not only on a morphological but also on a genetic basis. Tumors with different specific gene fusions may have consistent, unique clinical manifestations and morphological features (18). The most common gene fusions in Xp11.2 tRCCs are the TFE3 gene on $\mathrm{Xp} 11.2$ with $P R C C$ at $1 \mathrm{q} 21$ and TFE3 with $A S P L$ at $17 \mathrm{q} 25$, which arise from the translocations $\mathrm{t}(\mathrm{X} ; 1)(\mathrm{p} 11.2 ; \mathrm{q} 21)(19)$ and $\mathrm{t}(\mathrm{X} ; 17)$ (p11.2;q25.3) (20). The most common subtype is ASPL-TFE3 tRCC. Their morphology is mostly associated with the "classic" one: papillary/pseudopapillary architecture, large epithelial cell with voluminous cytoplasm, and psammoma bodies $(21,22)$. On the other hand, PRCC-TFE3 tRCC is the first documented case of $\operatorname{Xp} 11.2$ tRCC $(23,24)$. The typical histological pattern is compact architecture, less voluminous cytoplasm or clearing cytoplasm, and fewer psammoma bodies. Xp11.2 tRCC with NONO-TFE3 and SFPQ-TFE3 are less common subtypes that show a combination of nested to papillary architecture with a secretory endometrioid appearance and subnuclear vacuoles, like clear cell papillary RCC. Psammomatous calcifications are easily noticed in these tumors (15). So far, there are only 10 reported cases of RBM10-TFE3 RCCs. They have sheet, solid, papillary, and trabecular architecture, with clear to eosinophilic cytoplasm, which mimic the typical morphology of TFEB/t(6:11) RCC (25). Two rare cases of Xp11.2 tRCC have been reported since 2019: MED15-TFE3 tRCC (26) and NEAT1-TFE3 tRCC (27). Most parts of MED15-TFE3 tRCCs are solid and cystic structures, but they also have a solid and small nested pattern. The cytoplasm is voluminous eosinophilic. NEAT1-TFE3 tRCCs have abundant psammoma bodies and a predominantly alveolar/nested pattern. The tumors demonstrate large epithelioid and small lymphocyte-like cells. The rest of the Xp11.2 tRCCs [CLTCTFE3 (28), DVL2-TFE3 (15), LUC7L3-TFE3, KHSRP-TFE3, KHDRBS2-TFE3 (29), PARP14-TFE3 (30), KAT6A-TFE3 27), GRIPAP1-TFE3 (31)] have no distinctive histological patterns, probably because some fusion types were detected in nextgeneration sequencing.
However, an unreported VCP-TFE3 fusion transcript due to $\mathrm{t}(\mathrm{x} ; 9)(\mathrm{p} 11.23 ; \mathrm{p} 13.3)$ was found in a 17-year-old female in our study. The VCP-TFE3 fusion was found between VCP exon 11 and TFE3 exon 6 and between VCP exon 12 and TFE3 exon 6 . One article reported VCP-TFE3 fusion found in a perivascular epithelioid cell tumor (PEComa) arising in the pancreas of a 69year-old male (32). This case showed VCP-TFE3 fusion between VCP exon 11 and TFE3 exon 6. Our case showed a pure epithelioid morphology with a predominantly nested/alveolar (about 5\% papillary/pseudopapillary) growth pattern. The tumor cells were large and polygonal with eosinophilic to clear cytoplasm. The nuclei varied from small to exceptionally large focally and demonstrated prominent nucleoli and intranuclear inclusions. No psammoma bodies or melanin pigments were noticed. Overall, the morphology of VCP-TFE3 tRCC is similar to that of clear cell RCC, which is easy to be misdiagnosed. Integration of morphological, immunohistochemical, and molecular methods is often necessary for the precise diagnosis and optimal clinical management of Xp11.2 tRCCs.

As mentioned before, this disease has two distinct disease progression processes in different populations. Xp11.2 tRCC has an indolent course in children, while it commonly has an aggressive one in adult patients. In our study, three tumors affected children, and the oldest patient examined was 20 years old. This probably partially explained why most of our patients had good prognosis even with lymph node metastasis, except for the patient with the VCP-TFE3 fusion. It should be noted that different fusion subtypes within the same translocation-associated neoplasm may not only influence biological features but also be associated with clinical outcomes. Previous studies showed that PRCC-TFE3 presented at a lower stage and less metastatic frequency than did other tRCCs, such as ASPL-TFE3 (33). The tendency for $P R C C-T F E 3$ tRCC to recur late warrants long-term follow-up. The same as in the literature, one of our patients with $A S P L-T F E 3$ fusion had local lymph node metastasis; the others with ASPL-TFE3 and PRCC-TFE3 tRCC had none. Our 
VCP-TFE3 fusion patient came to us with multiple bone metastases at the first visit, which deceased 3 months later without any further treatment, probably indicating that VCPTFE3 has worse prognosis because of the fusion partner. Valosincontaining protein (VCP)/p97 (Cdc48) is a member of the ATP-binding protein family and is best known for its role in various important cellular events, such as protein homeostasis, but is also involved in regulating critical signaling pathways including cell cycle regulation. Additionally, clinical studies have identified a correlation between elevated VCP expression and the progression, prognosis, and metastatic potential of esophageal carcinoma (34), colorectal carcinoma (35), prostate cancer (36), non-small cell lung carcinoma (37), and pancreatic cancer. Furthermore, VCP was reported to be one of the few known recurrent amplicons at the DNA level associated with tumor metastasis (38), which is probably related to nuclear factor kappa B (NF- $\mathrm{KB}$ ) signaling pathway (39). These findings probably propose the expression level of VCP as a useful marker for the progression of these cancers. In addition, a potential antiapoptotic role of VCP was first described in 1991 by Shirogane et al. (40) and was further substantiated by the fact that increased levels of VCP strongly correlate with poor prognosis and metastasis of various human cancers. Our patient with the VCP-TFE3 fusion had distant metastasis as an initial symptom and had a short survival period, which is probably related to the VCP-TFE3 fusion. Although whether the fusion status is an independent predictor of outcomes is debated, these examples highlight the potential for the fusion subtype to impact patient care. Ellis et al. (33) mentioned a hypothesis that fusion types could highly possibly influence the tumor prognosis in Xp11.2 tRCCs with enough cases. Other researchers also noticed the same phenomenon in other malignant neoplasms such as Ewing sarcomas, primary mucoepidermoid carcinoma, and alveolar rhabdomyosarcomas. The type 1 EWS-FLI1 fusion (fusion of exon 6 of FLI1 with exon 7 of EWS) has better and favorable prognosis than other variant EWS-FLI1 gene fusions (41-43). Furthermore, CRTC3-MAML2 tends to have a smaller tumor size and better prognosis than does CRTC1-MAML2, although these data have no statistical significance because of the low number of CRTC3-MAML2 cases $(44,45)$. Interestingly, the same is true for alveolar rhabdomyosarcomas. Cases with the PAX3-FOXO1 gene fusion have worse outcome than those with the PAX7-FOXO1 fusion (46). These different associations additionally support the notion that the fusion proteins encoded by these chromosomal translocations are probably central to the biology of these tumors.

Currently, the treatment for Xp11.2 tRCC is still unestablished, and no clinical studies with a large sample size are being conducted. Most cases followed the guidelines for conventional RCC. Surgical therapy plays a primary role and is currently focusing on organ preservation; however, this is based upon tumor localization and institutional experience. The therapy for metastatic Xp11.2 RCC is not different from that for conventional RCC. Therapies targeting vascular endothelial growth factor receptor (VEGF), mammalian target of rapamycin, and sorafenib may benefit patients with Xp11.2 tRCC (13). The prognosis is controversial since Xp11.2 tRCC has an indolent behavior in children; however, new reports on an aggressive clinical course in adults have been published as well (14). In multivariate analysis, only older age or an advanced stage at presentation predicted death. In our cohort, three patients were under 18 years old. The patient with PRCC-TFE3 fusion was 20 years old. This $P R C C-T F E 3$ fusion patient and one of those with the ASPL-TFE3 fusion (4 years old) were in the early stage and good condition, and one ASPL-TFE3 RCC patient (9 years old) had lymph node metastasis. All three patients showed no recurrence after a 3-year follow-up. Our patient with the VCP-TFE3 fusion (17 years old) had distant metastasis as an initial symptom and died of the disease after 3 months, probably indicating that the fusion type could influence prognosis.

Increased understanding of the clinical, pathological, molecular, and prognostic heterogeneity of Xp11.2 tRCC, since their official recognition in 2004, provides the opportunity to identify prognostic biomarkers and to understand the reasons for tumor aggression. The characteristics of these four cases showed some uniformity, but still have some differences. Immunohistochemistry results revealed tumor cells positive for TFE3, but have no consistency in other markers. Therefore, the uniform and definitive diagnostic standards of the tumors are uncertain. The prognosis of Xp11.2 RCC is still unclear because of the low appearance of series including a great number of patients and the short follow-up period. In this study, we discovered an unreported VCP-TFE3 tRCC that had worse prognosis compared to other fusion Xp11.2 RCC. It is probable that the fusion type could influence therapy and prognosis. RNA sequencing probably needs to be done; even FISH detection has been conducted. Detection of the relationship between the gene changes and clinical parameters needs more cases and research. Hence, more cases and findings are required to elaborate the standards of all the tumor subtypes.

\section{DATA AVAILABILITY STATEMENT}

The original contributions presented in the study are included in the article. Further inquiries can be directed to the corresponding authors.

\section{ETHICS STATEMENT}

The studies involving human participants were reviewed and approved by the Guangdong Provincial People's Hospital Ethics Committee. Written informed consent to participate in this study was provided by the participants' legal guardian/next of kin. Written informed consent was obtained from the individual(s) and minor(s)' legal guardian/next of kin for the publication of any potentially identifiable images or data included in this article.

\section{AUTHOR CONTRIBUTIONS}

YG and XL were responsible for study conception and design. QZ, DL, and LL contributed to the acquisition of data (acquired and managed patients, provided facilities, etc.). YG wrote the manuscript. HW and ZL supervised the study. All authors read and approved the final manuscript. All authors contributed to the article and approved the submitted version. 


\section{REFERENCES}

1. Argani P, Ladanyi M, Eble JN, Sauter G, Epstein JI, Sesterhenn M, et al. Renal Carcinoma Associated With Xp11.2 Translocations/TFE3 Gene Fusions. In: Eble JN, Sauter G, Epstein JI, et al, editors. Tumors of the Urinary System and Male Genital Organs. Lyon: IARC (2004). p. 37-8.

2. Argani P, Cheville J, Ladanyi M, Moch H, Humphrey PA, Ulbright TM. MiT Family Translocation Renal Cell Carcinoma. In: Moch H, Humphrey PA, Ulbright TM, editors. WHO Classification of Tumours of the Urinary System and Male Genital Organs. Lyon: IARC Press (2016). p. 33-4.

3. Lei X, Xiaocheng C, Ning L, Zhen W, Baolei M, Weidong G, et al. PRCCTFE3 Dual-Fusion FISH Assay: A New Method for Identifying PRCC-TFE3 Renal Cell Carcinoma in Paraffin-Embedded Tissue. PloS One (2017) 12: e0185337. doi: 10.1371/journal.pone.0185337

4. Argani P, Olgac S, Tickoo SK, Goldfischer M, Moch H, Chan DY, et al. Xp11 Translocation Renal Cell Carcinoma in Adults: Expanded Clinical, Pathologic, and Genetic Spectrum. Am J Surg Pathol (2007) 31:1149-60. doi: 10.1097/PAS.0b013e318031fff

5. Feinman R, Qiu WQ, Pearse RN, Nikolajczyk BS, Sen R, Sheffery M, et al. PU.1 and an HLH Family Member Contribute to the Myeloid-Specific Transcription of the Fc Gamma RIIIA Promoter. EMBO J (1994) 13:385260. doi: 10.1002/j.1460-2075.1994.tb06696.x

6. Wang XT, Xia QY, Ye SB, Wang X, Li R, Fang R, et al. RNA Sequencing of Xp11 Translocation-Associated Cancers Reveals Novel Gene Fusions and Distinctive Clinicopathologic Correlations. Mod Pathol (2018) 31:1346-60. doi: 10.1038/s41379-018-0051-5

7. Tretiakova MS, Wang W, Wu Y, Tykodi SS, True L, Liu YJ. Gene Fusion Analysis in Renal Cell Carcinoma by FusionPlex RNA-Sequencing and Correlations of Molecular Findings With Y, Mukai H, Clinicopathological Features. Genes Chromosomes Cancer (2020) 59:40-9. doi: 10.1002/gcc.22798

8. Lang XP, Pan J, Yang CX, Chen P, Shi CC, Hong Y, et al. A Renal Cell Carcinoma With EWSR1-TFE3 Fusion Gene. Genes Chromosomes Cancer (2020) 59:325-9. doi: 10.1002/gcc.22830

9. Argani P, Ladanyi M. Translocation Carcinomas of the Kidney. Clin Lab Med (2005) 25:363-78. doi: 10.1016/j.cll.2005.01.008

10. Argani P, Lal P, Hutchinson B, Lui MY, Reuter VE, Ladanyi M. Aberrant Nuclear Immunoreactivity for TFE3 in Neoplasms With TFE3 Gene Fusions: A Sensitive and Specific Immunohistochemical Assay. Am J Surg Pathol (2003) 27:750-61. doi: 10.1097/00000478-200306000-00005

11. Wu A, Kunju LP, Cheng L, Shah RB. Renal Cell Carcinoma in Children and Young Adults: Analysis of Clinicopathological, Immunohistochemical and Molecular Characteristics With an Emphasis on the Spectrum of Xp11.2 Translocation-Associated and Unusual Clear Cell Subtypes. Histopathology (2008) 53:533-44. doi: 10.1111/j.1365-2559.2008.03151

12. Komai Y, Fujiwara M, Fujii Y, Mukai H, Yonese J, Kawakami S, et al. Adult Xp11 Translocation Renal Cell Carcinoma Diagnosed by Cytogenetics and Immunohistochemistry. Clin Cancer Res (2009) 15:1170-6. doi: 10.1158/ 1078-0432.CCR-08-1183

13. Camparo P, Vasiliu V, Molinie V, Couturier J, Dykema KJ, Petillo D, et al. Renal Translocation Carcinomas: Clinicopathologic, Immunohistochemical, and Gene Expression Profiling Analysis of 31 Cases With a Review of the Literature. Am J Surg Pathol (2008) 32:656-70. doi: 10.1097/PAS. 0b013e3181609914

14. Kuthi L, Somorácz Á, Micsik T, Jenei A, Hajdu A, Sejben I, et al. Clinicopathological Findings on 28 Cases With XP11.2 Renal Cell Carcinoma. Pathol Oncol Res (2020) 26:2123-33. doi: 10.1007/s12253-019-00792-0

15. Argani P, Zhong M, Reuter VE, Fallon JT, Epstein JI, Netto GJ, et al. TFE3Fusion Variant Analysis Defines Specific Clinicopathologic Associations Among Xp11 Translocation Cancers. Am J Surg Pathol (2016) 40:723-37. doi: 10.1097/PAS.0000000000000631

16. Argani P, Lui MY, Couturier J, Bouvier R, Fournet JC, Ladanyi M. A Novel CLTC-TFE3 Gene Fusion in Pediatric Renal Adenocarcinoma With T(X; 17) (P11.2; Q23). Oncogene (2003) 22:5374-8. doi: 10.1038/sj.onc.1206686

17. Gandhi JS, Malik F, Amin MB, Argani P, Bahrami A. MiT Family Translocation Renal Cell Carcinomas: A 15th Anniversary Update. Histol Histopathol (2020) 35:125-36. doi: 10.14670/HH-18-159

18. Xia QY, Wang Z, Chen N, Gan HL, Teng XD, Shi SS, et al. Xp11.2 Translocation Renal Cell Carcinoma With NONO-TFE3 Gene Fusion:
Morphology, Prognosis, and Potential Pitfall in Detecting TFE3 Gene Rearrangement. Mod Pathol (2017) 30:416-26. doi: 10.1038/modpathol. 2016.204

19. Shipley JM, Birdsall S, Clark J, Crew J, Gill S, Linehan M, et al. Mapping the X Chromosome Breakpoint in Two Papillary Renal Cell Carcinoma Cell Lines With a $\mathrm{T}(\mathrm{X} ; 1)(\mathrm{p} 11.2 ; \mathrm{q} 21.2)$ and the First Report of a Female Case. Cytogenet Cell Genet (1995) 71:280-4. doi: 10.1159/000134127

20. Heimann P, EI Housni H, Ogur G, Weterman MA, Petty EM, Vassart G. Fusion of a Novel Gene, RCC17, to the TFE3 Gene in T(X;17) (P11.2; Q25.3)Bearing Papillary Renal Cell Carcinomas. Cancer Res (2001) 61:4130-5. doi: 10.1002/1097-0142(20010515)91:10<1956::AID-CNCR1219>3.0.CO;2-F

21. Akgul M, Saeed O, Levy D, Mann SA, Cheng L, Grignon DJ, et al. Morphologic and Immunohistochemical Characteristics of Fluorescent in Situ Hybridization Confirmed TFE3-Gene Fusion Associated Renal Cell Carcinoma: A Single Institutional Cohort. Am J Surg Pathol (2020) 44:1450-8. doi: 10.1097/PAS.0000000000001541

22. Argani P, Antonescu CR, Illei PB, Lui MY, Timmons CF, Newbury R, et al. Primary Renal Neoplasms With the ASPL-TFE3 Gene Fusion of Alveolar Soft Part Sarcoma: A Distinctive Tumor Entity Previously Included Among Renal Cell Carcinomas of Children and Adolescents. Am J Pathol (2001) 59:179-92. doi: 10.1016/S0002-9440(10)61684-7

23. Green WM, Yonescu R, Morsberger L, Morris K, Netto GJ, Epstein JI, et al. Utilization of a TFE3 Break-Apart FISH Assay in a Renal Tumor Consultation Service. Am J Surg Pathol (2013) 37:1150-63. doi: 10.1097/PAS. 0b013e31828a69ae

24. Argani P, Antonescu CR, Couturier J, Fournet JC, Sciot R, Debiec-Rychter M, et al. PRCC-TFE3 Renal Carcinomas: Morphologic, Immunohistochemical, Ultrastructural, and Molecular Analysis of an Entity Associated With the T (X;1)(P11.2;q21). Am J Surg Pathol (2002) 26:1553-66. doi: 10.1097/ 00000478-200212000-00003

25. Xia QY, Wang XT, Zhan XM, Tan X, Chen H, Liu Y, et al. Xp11 Translocation Renal Cell Carcinomas (RCCs) With RBM10-TFE3 Gene Fusion Demonstrating Melanotic Features and Overlapping Morphology With T $(6 ; 11)$ RCC: Interest and Diagnostic Pitfall in Detecting a Paracentric Inversion of TFE3. Am J Surg Pathol (2017) 41:663-76. doi: 10.1097/ PAS.0000000000000837

26. Ye H, Qin S, Li N, Lin M, Xu Y, Li X. A Rare Partner of TFE3 in the Xp11 Translocation Renal Cell Carcinoma: Clinicopathological Analyses and Detection of MED15-TFE3 Fusion. BioMed Res Int (2019) 11:5974089. doi: $10.1155 / 2019 / 5974089$

27. Pei J, Cooper H, Flieder DB, Talarchek JN, Al-Saleem T, Uzzo RG, et al. NEAT1-TFE3 and KAT6A-TFE3 Renal Cell Carcinomas, New Members of MiT Family Translocation Renal Cell Carcinoma. Mod Pathol (2019) 32:710 6. doi: 10.1038/s41379-018-0191-7

28. Argani P, Ladanyi M. Distinctive Neoplasms Characterised by Specific Chromosomal Translocations Comprise a Significant Proportion of Pediatric Renal Cell Carcinomas. Pathology (2003) 35:492-8. doi: 10.1080/ 00313020310001619901

29. Malouf GG, Su X, Yao H, Gao J, Xiong L, He Q, et al. Next-Generation Sequencing of Translocation Renal Cell Carcinoma Reveals Novel RNA Splicing Partners and Frequent Mutations of Chromatin-Remodeling Genes. Clin Cancer Res (2014) 20:4129-40. doi: 10.1158/1078-0432.CCR13-3036

30. Huang W, Goldfischer M, Babayeva S, Mao Y, Volyanskyy K, Dimitrova N, et al. Identification of a Novel PARP14-TFE3 Gene Fusion From 10-Year-Old FFPE Tissue by RNA-Seq. Genes Chromosomes Cancer (2015) 54:500-5. doi: $10.1002 /$ gcc. 22261

31. Classe M, Malouf GG, Su X, Yao H, Thompson EJ, Doss DJ, et al. Incidence, Clinicopathological Features and Fusion Transcript Landscape of Translocation Renal Cell Carcinomas. Histopathology (2017) 70:1089-97. doi: $10.1111 /$ his. 13167

32. Zhu G, Benayed R, Ho C, Mullaney K, Sukhadia P, Rios K, et al. Diagnosis of Known Sarcoma Fusions and Novel Fusion Partners by Targeted RNA Sequencing With Identification of a Recurrent ACTB-FOSB Fusion in Pseudomyogenic Hemangioendothelioma. Mod Pathol (2019) 32:609-20. doi: 10.1038/s41379-018-0175-7

33. Ellis CL, Eble JN, Subhawong AP, Martignoni G, Zhong M, Ladanyi M, et al. Clinical Heterogeneity of Xp11 Translocation Renal Cell Carcinoma: Impact 
of Fusion Subtype, Age, and Stage. Mod Pathol (2014) 27:875-86. doi: 10.1038/modpathol.2013.208

34. Yamamoto S, Tomita Y, Hoshida Y, Iizuka N, Kidogami S, Miyata H, et al. Expression Level of Valosin-Containing Protein (P97) Is Associated With Prognosis of Esophageal Carcinoma. Clin Cancer Res (2004) 10:5558-65. doi: 10.1158/1078-0432.CCR-0723-03

35. Yamamoto S, Tomita Y, Hoshida Y, Sakon M, Kameyama M, Imaoka S, et al. Expression of Valosin-Containing Protein in Colorectal Carcinomas as a Predictor for Disease Recurrence and Prognosis. Clin Cancer Res (2004) 10:651-7. doi: 10.1158/1078-0432.ccr-1576-03

36. Tsujimoto $\mathrm{Y}$, Tomita $\mathrm{Y}$, Hoshida $\mathrm{Y}$, Kono T, Oka T, Yamamoto $\mathrm{S}$, et al. Elevated Expression of Valosin-Containing Protein (P97) Is Associated With Poor Prognosis of Prostate Cancer. Clin Cancer Res (2004) 10:3007-12. doi: 10.1158/1078-0432.ccr-03-0191

37. Valle CW, Min T, Bodas M, Mazur S, Begum S, Tang D, et al. Critical Role of VCP/p97 in the Pathogenesis and Progression of Non-Small Cell Lung Carcinoma. PloS One (2011) 6:e29073. doi: 10.1371/journal. pone. 0029073

38. Jones S, Zhang X, Parsons DW, Lin JC, Leary RJ, Angenendt P, et al. Core Signaling Pathways in Human Pancreatic Cancers Revealed by Global Genomic Analyses. Science (2008) 26:1801-6. doi: 10.1126/science. 1164368

39. Long XH, Zhang ZH, Liu ZL, Huang SH, Luo QF. Inhibiting ValosinContaining Protein Suppresses Osteosarcoma Cell Metastasis via AKT/ nuclear Factor of Kappa B Signaling Pathway In Vitro. Indian J Pathol Microbiol (2013) 56:190-5. doi: 10.4103/0377-4929.120358

40. Shirogane T, Fukada T, Muller JM, Shima DT, Hibi M, Hirano T. Synergistic Roles for Pim-1 and C-Myc in STAT3-Mediated Cell Cycle Progression and Antiapoptosis. Immunity (1999) 11:709-19. doi: 10.1016/s1074-7613(00)80145-4

41. Lin PP, Brody RI, Hamelin AC, Bradner JE, Healey JH, Ladanyi M. Differential Transactivation by Alternative EWS-FLI1 Fusion Proteins Correlates With Clinical Heterogeneity in Ewing's Sarcoma. Cancer Res (1999) 59:1428-32.

42. de Alava E, Panizo A, Antonescu CR, Huvos AG, Pardo-Mindán FJ, Barr FG, et al. Association of EWS-FLI1 Type 1 Fusion With Lower Proliferative Rate in Ewing's Sarcoma. Am J Pathol (2000) 156:849-55. doi: 10.1016/S0002-9440 (10)64953-X

43. de Alava E, Kawai A, Healey JH, Fligman I, Meyers PA, Huvos AG, et al. EWSFLI1 Fusion Transcript Structure Is an Independent Determinant of Prognosis in Ewing's Sarcoma. J Clin Oncol (1998) 16:1248-55. doi: 10.1200/ JCO.1998.16.4.1248

44. Zhang X, Bai QM, Yao QL, Ji G, Chang H, Han J, et al. MAML2 Gene Rearrangement, Fusion Patterns and Clinicopathological Characteristics in Primary Pulmonary Mucoepidermoid Carcinoma. Zhonghua Bing Li Xue Za Zhi (2021) 50(8):891-898. Chinese. doi: 10.3760/cma.j.cn112151-2021042100308

45. Toper MH, Sarioglu S. Molecular Pathology of Salivary Gland Neoplasms: Diagnostic, Prognostic, and Predictive Perspective. Adv Anat Pathol (2021) 28:81-93. doi: 10.1097/PAP.0000000000000291

46. Skapek SX, Anderson J, Barr FG, Bridge JA, Gastier-Foster JM, Parham DM, et al. PAX-FOXO1 Fusion Status Drives Unfavorable Outcome for Children With Rhabdomyosarcoma: A Children's Oncology Group Report. Pediatr Blood Cancer (2013) 60:1411-7. doi: 10.1002/pbc.24532

Conflict of Interest: The authors declare that the research was conducted in the absence of any commercial or financial relationships that could be construed as a potential conflict of interest.

Publisher's Note: All claims expressed in this article are solely those of the authors and do not necessarily represent those of their affiliated organizations, or those of the publisher, the editors and the reviewers. Any product that may be evaluated in this article, or claim that may be made by its manufacturer, is not guaranteed or endorsed by the publisher.

Copyright $\odot 2021$ Ge, Lin, Zhang, Lin, Luo, Wang and Li. This is an open-access article distributed under the terms of the Creative Commons Attribution License (CC BY). The use, distribution or reproduction in other forums is permitted, provided the original author(s) and the copyright owner(s) are credited and that the original publication in this journal is cited, in accordance with accepted academic practice. No use, distribution or reproduction is permitted which does not comply with these terms. 